\title{
Reproductive ecology of the Kandyan Day Gecko, Cnemaspis kandiana, in Gannoruwa Forest Reserve
}

\author{
Ruchira Somaweera \\ Department of Zoology, Faculty of Science, University of Peradeniya, Peradeniya.
}

Revised: 10 April 2008 ; Accepted: 18 August 2008

\begin{abstract}
Breeding habitats and environmental conditions preferred by Cnemaspis kandiana, its oviposition and reproduction aspects, its interactions with other species in the nesting habitat, and the mode of oviposition were investigated at the Gannoruwa Forest Reserve, Sri Lanka, during fortnightly field surveys from June 2005 to January 2006. Eleven egg clusters in five caves at Gannoruwa were sampled and data on the environmental conditions inside the caves, number of hatched and unhatched eggs, hatchlings, adults and other faunal species in the nesting habitat recorded. Six eggs were incubated in the laboratory. At the nesting sites, ambient temperature varied from $23-30{ }^{\circ} \mathrm{C}$ and light intensity from 0-350 lux. The eggs were predominantly laid as pairs (on $85 \%$ occasions) suggesting that $C$. kandiana has invariant clutch size. The hatched and unhatched eggs at each location varied from 1 to over 100, though the maximum number of unhatched developing eggs found at a given time was 18 , i.e., a cluster size to vary from 1-18 eggs. Eggs tend to hatch in pairs, after an apparent incubation period of 39-58 days. The hatchlings had a total length of 23.5-25.8 mm. No interaction with regard to reproduction was found between $C$. kandiana and any other animals at the breeding sites. The egg-laying in this species is probably a combined effect of site fidelity of a female and communal nesting. This might be due to relative scarcity of preferred habitats in the study area.
\end{abstract}

Keywords: Clutch size, cnemaspis kandiana, communal nesting, Gecko, reproduction, Sri Lanka.

\section{INTRODUCTION}

Oriental Dwarf or Day geckos of the genus Cnemaspis Strauch (1887) are represented by $\sim 70$ species in South and Southeast Asia, with additional forms in tropical Africa ${ }^{1-12}$. They are represented in Sri Lanka by 21 member species ${ }^{12}$. Though the taxonomy of these members has received considerable attention, hardly anything is known about the biology of the various species. The reproductive ecology of Cnemaspis is interesting because of the communal nesting exhibited by some species. To date only ten species, viz., C. alwisi, C. clivicola, C. kallima, C. kandiana and C. upendrai from Sri Lanka ${ }^{12,13}$, C. baueri from West Malaysia ${ }^{6}$, C. indica from Western Ghats ${ }^{14}, C$. cf. indraneildasii from India ${ }^{15}$, C. kendallii from Singapore ${ }^{16}$ and C. mysoriensis from India ${ }^{17}$, have been reported to exhibit communal nesting. However, at least five other Indian species of the genus resort to communal nesting (personal communication, Sayanthan Biswas), with the possibility of some of these exhibiting interspecific communal oviposition ${ }^{15}$.

It has been reported on the possibility of more than one female of $C$. kandiana laying eggs at the same site ${ }^{13,18}$. Some subsequent authors ${ }^{19}$ have referred to the above same study but without providing any new information. Ratnayake ${ }^{20}$, de Silva et al. ${ }^{21}$ and Manamendra-Arachchi et al. ${ }^{12}$ other study graphs have provided brief notes and a photograph of communal nesting sites under the bark of a tree and among rocks ${ }^{12,20-21}$.

The present study addresses four issues in C. kandiana, i.e. (1) the breeding habitat and its environmental correlates, (2) some aspects of its oviposition and reproduction including incubation period, clutch (considered here as the total number of eggs laid by a single female at a single time) cluster (total hatched + un-hatched eggs at the same location) sizes, and size of hatchlings, (3) interactions with other species at nesting sites, and (4) the biological basis of communal nesting. 


\section{METHODS AND MATERIALS}

Study species: Originally described as Gymnodactylus kandianus, the species C. kandiana has served as a catchall species in the region. Until recently, $C$. kandiana was considered to be a widespread species in Asia. Some authors described C. kandiana as widespread in southern India, Sri Lanka and ranging from the Andaman Islands to Indonesia ${ }^{22}$. However, based on recent studies, it is considered that C. kandiana sensu stricto is restricted to the mid-central hills of Sri Lanka, specifically the moist forests of the Central Province between 400-700 m.s.l., with rainfall of $>2,500 \mathrm{~mm}$ per year ${ }^{12}$. Furthermore, C. andersonii, C. malabarica and C. wicksii previously synonymized are now considered as valid species ${ }^{12}$.

Study site: The site of the study was the Gannoruwa Forest Reserve [GFR] ( $\left.7^{\circ} 17^{\prime} \mathrm{N}, 80^{\circ} 36^{\prime} \mathrm{E}\right)$ in Kandy District of the Central Province. The mean annual temperature is $24.1{ }^{\circ} \mathrm{C}$ with lowest temperatures in January and highest in April. Mean annual rainfall is $2131 \mathrm{~mm}$, derived from both the north-east and south-west monsoons ${ }^{23}$. The area belongs to the Kandy-Upper Mahaweli floristic zone $^{24}$ and Intermediate Wet Evergreen Forest ecotone ${ }^{23}$. The GFR contains several medium-sized and numerous small-sized talus (boulder) caves, i.e. found at the base of a cliff or slope and usually the result of a rock-slide type action, and crevice caves, i.e. found where a cliff face has pulled away from the stable rock face, creating a crack or crevice. Five study caves were selected, four near the Dankella entrance and the other above the Bulawaththa entrance, based on the presence of egg clusters, nature and size of the cave, surrounding vegetation and ease of access.

\section{Field sampling:}

a) the caves: The study included 14 consecutive sampling sessions conducted between 18 June 2005 and 29 January 2006. The GFR was visited fortnightly during each month except in June 2005 when only a single visit was made. A typical sampling session lasted from $c a 0700-1400 \mathrm{~h}$. The order of visiting the caves was rotated during subsequent visits to reduce the bias of time of sampling. During the initial visit for detailed sampling, the following information was recorded for each cave. 1) GPS location (Using a $e$ Trex Venture GPS), 2) maximum height and width of the cave entrance, and maximum depth of the cave (using an Freemans 5) m flexiruler), 3) geographical orientation of the opening (using an Silva ${ }^{\circledR}$ Sweden Type 4 compass), 4) ground substrate, and 5) surrounding vegetation. Temperature (in ${ }^{\circ} \mathrm{C}$ using a field thermometer) at mid-depth of each cave was recorded during all subsequent visits, but light intensity (in lux using a Lutron LX 101 Lux meter) at mid-depth of the caves was recorded only during a single visit. At least a single night visit was made to each cave. Additionally, random searches for geckos were done on tree trunks, buttresses, among leaflitter, under stones and $\operatorname{logs}$ at the GFR, Udawattakele in Kandy and lower Hantana at Peradeniya.

b) eggs: Representative clusters were selected for observation in all the caves and the number of eggs (unhatched + hatched) in those clusters were counted, numbered with a 2B lead pencil and photographed using an Olympus C740 digital camera. Representative eggs from different clusters were measured using Mitutoyo digital Vernier callipers (to the nearest $0.05 \mathrm{~mm}$ ). Depending on the rate of oviposition (frequency of addition of new eggs), rate of hatching (considering incubation time, synchrony and asynchrony of hatching) and maximum number of unhatched eggs present at a given time (considering the cluster and clutch sizes), it was determined whether the particular cluster represented a communal nesting site or a non-communal nesting site within the study period.

c) adults: Whenever possible adults were caught manually, sexed, measured as above and marked using a technique similar to that used by Werner \& Chou ${ }^{16}$, where a $\sim 5 \times 5$ $\mathrm{mm}$ piece of $3 \mathrm{M}$ Scotchlite $8830 \AA$ silver marking film with a serial number written on it using a black fine felt pen was pasted on the dorsal side between the hind limbs. The marked animals were released where they had been caught and the markings were clearly reflected and were visible when a light beam from a head-torch was directed. Some individuals were photographed in situ. No geckos were killed or harmed in this study.

d) other animals in the caves: Presence of other vertebrates and invertebrates inside the caves was recorded and observations (such as feeding) were made to investigate whether there were any interactions between them and C. kandiana. Three adult individuals of the endemic mollusk Ratnadvipia irradians (which was very common inside the caves) collected from caves 1, 3 and 4, were kept in captivity in separate jars for a week and they were offered broken parts of egg shells collected from the caves to observe whether they fed on them.

Ex-situ studies:

Two eggs from each of three representative egg clusters found in three caves were incubated under artificial conditions. The two eggs collected on 12 June 2005 (during the reconnaissance survey) from cluster 1 of cave 2 had not been present in the site on 11 June 2005, showing that they were laid between the two sampling 
sessions. Eggs from different caves were placed on tissue paper in separate glass jars with the mouth covered by a fine mesh. The bottles were placed in a shady place inside a room with an ambient temperature varying between $24 \pm 2{ }^{\circ} \mathrm{C}$. The length of the eggs was measured, and changes in colour recorded at $2 \mathrm{~d}$ intervals. The hatchlings were measured for snout-vent length (SVL) and tail length (TL), photographed and released after one day of hatching, into the same cave from where the eggs had been collected. They were not sexed as it was difficult to accurately sex hatchlings without dissection.

\section{RESULTS}

\section{a. The caves:}

The five caves sampled had entrances with dimensions of 102-260 cm (height), 208-780 cm (width) and 193$572 \mathrm{~cm}$ (depth). All caves had boulders and a thin layer of soil on the ground. Being caves with large entrances (cave mouths), caves 1, 2 and 4 had no permanently dark area while caves 3 and 5 had permanently dark interiors. Cave 1, located in the border of the reserve, was frequently used by villagers to store firewood and there were signs of temporary fires inside the cave. A drip ledge was observed in the cave indicating its use in ancient times.

\section{b. Environmental conditions:}

Within the study period the ambient temperature varied between $2630{ }^{\circ} \mathrm{C}$ during the day (0700-1900 h) and between $2325^{\circ} \mathrm{C}$ during the night. Light intensity varied

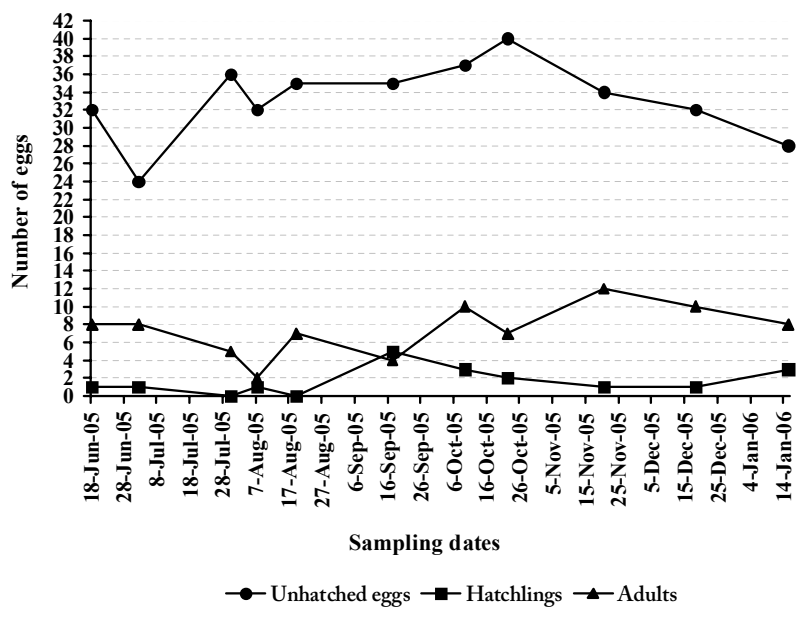

Figure 1: Fluctuations in the total number of eggs, hatchlings and adults recorded inside caves during sampling sessions which included all caves from 20-350 lux during the day. Light showers were noted in the area during July, August, December in the year in 2005 and in January 2006.

\section{c. Eggs, hatchlings and adults:}

On six occasions, adults were observed near or on the clusters but egg laying was not observed. The number of developing eggs was high during October and November (Figure 1). New eggs were observed on 39 occasions during the study period, of which on five occasions (13\%) they were laid separately as singles; on 33 occasions $(85 \%)$ as pairs and on a single occasion $(2 \%)$ as a group of three eggs (Figure 2). Newly laid eggs had a diameter of $5.50 \pm 0.05 \mathrm{~mm}$. They were bright, clear white in colour, and almost round in shape with a slightly flattened side attached to the substrate. Of the 11 clusters, except for two, that were laid on flat surfaces of the cave wall, the others were placed in depressions or furrows in the cave wall which were facing away from the cave mouth (Figure 3 ). Thus, no direct sunlight fell on those even though sunlight reached the walls inside some caves. The exceptions were Cluster 2 of Cave 3 and Cluster 2 of Cave 2, which were also the largest clusters, and were on a flat surface of the wall beyond the reach of direct sunlight. There was an observable reduction in new eggs during rainy months. The minimum distance between two clusters in a cave was $55 \mathrm{~cm}$. Cluster 1 in Cave 2 was destroyed between 19 August 2005 and 11 September 2005 due to breaking off of a part of the

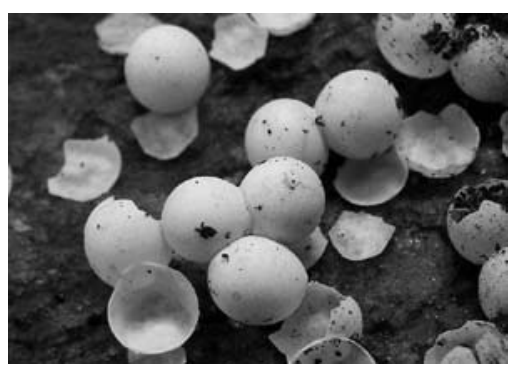

Figure 2: The only apparent triplet of eggs recorded during the study

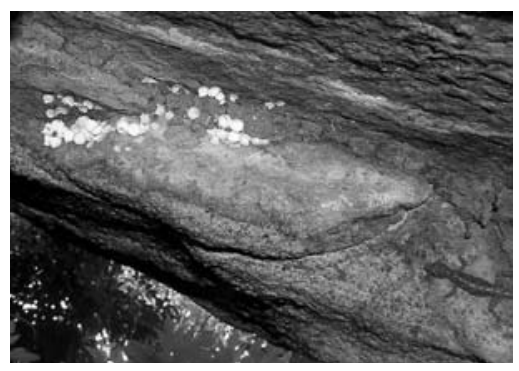

Figure 3: Typical egg deposition pattern facing the inside of the cave (An adult gecko is also visible in the right lower corner) 


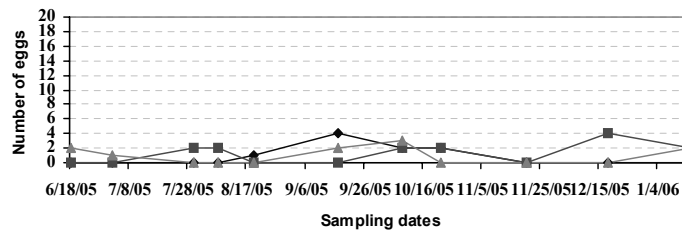

a. The three clutches at Cave 1

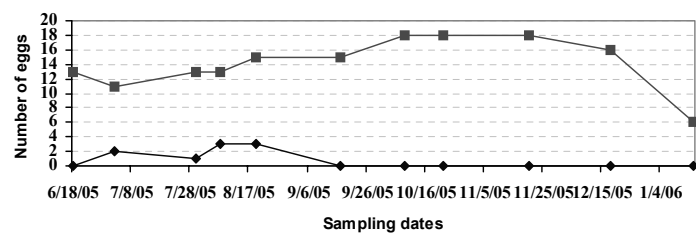

b. The two clutches at Cave 2
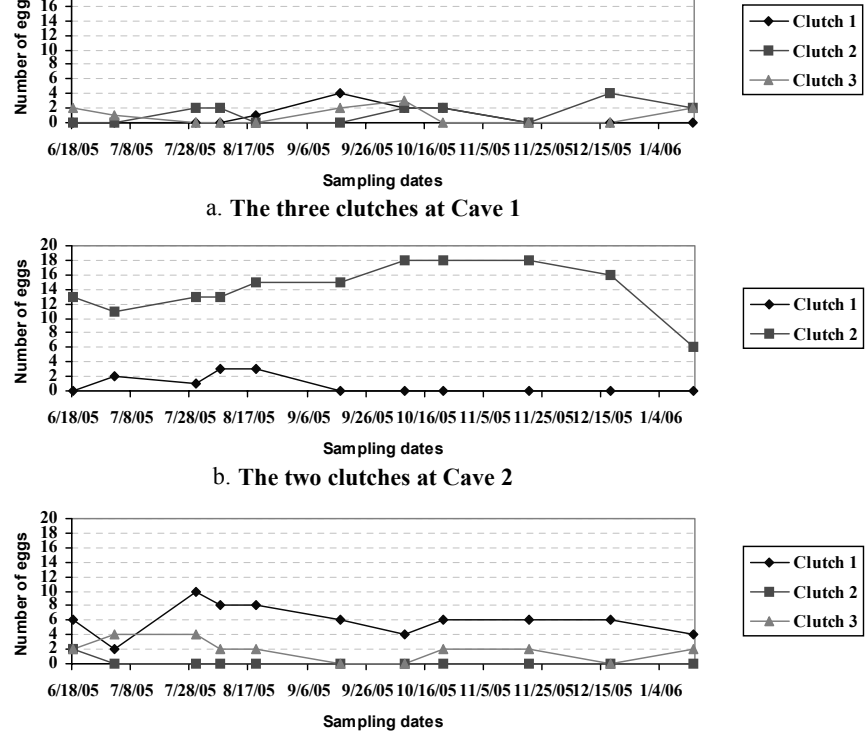

$\rightarrow-$ Clutch 2

c. The three clutches at Cave 3

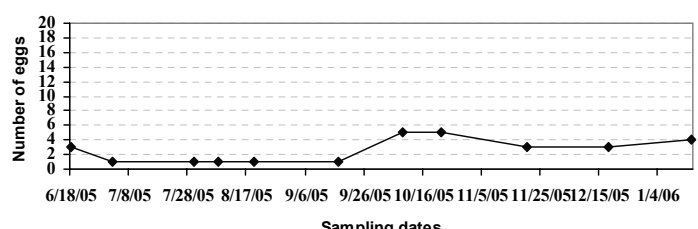

Sampling dates

d. The clutch at Cave 4

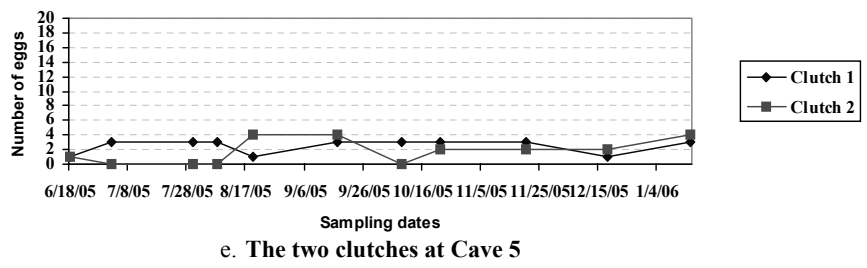

Figure 4: Fluctuations of the number of eggs in the clusters at the five caves at the GFR

wall of the cave [Figure 4b]. Cluster 2 of Cave 3 may have been abandoned, as no egg laying was observed at the site (Figure 4c). This site was selected for the study because freshly-hatched shells were initially present. The number of unhatched eggs (both developing and old unviable eggs) can be estimated only approximately, as fragmental remains of more recently deposited eggs were found on and among older ones that can result in counts being underestimated. The cluster size (hatched + un-hatched eggs in the same location) varied from one to over 100. But the maximum number of unhatched eggs found at a given time in a cluster was 18 (Figures $4 \mathrm{~b} \& 5$ ). No detectable colour changes were observed among the eggs in this cluster; hence it was presumed that it belonged to a single egg-laying cycle.

Both under in situ and laboratory conditions in general, eggs of $C$. kandiana laid as pairs hatch almost simultaneously. Under in situ conditions, eggs had an incubation period of approximately two months. Under laboratory conditions, the incubation period varied between an apparent minimum of 39 days and maximum of 58 days at $24.0 \pm 2{ }^{\circ} \mathrm{C}$ (Table 1). Also, darkening of the eggs was observed about 6-10 days prior to hatching.

The size of the hatchlings (Figure 6) varied in the range SVL: $11.90 \pm 0.40 \mathrm{~mm}$, TL: $12.75 \pm 0.75 \mathrm{~mm}$ (total length: $24.65 \pm 1.15 \mathrm{~mm}$ ) and they were active soon after birth. Hatchlings or very young juveniles were observed only on 15 occasions. The observed numbers were comparatively high in September 2005 (Figure 1).

Adults were observed on 46 occasions and they were more frequently seen during early mornings (before $0900 \mathrm{~h}$ ) and late evenings (after $1700 \mathrm{~h}$ ). No clear temporal change in the abundance of adults was 
observed between months. No inter-cave movements were recorded from the marked individuals. Of the 18 individuals caught from inside caves, 11 were females. The measurements of the females were as follows SVL: $33.95 \pm 3.20 \mathrm{~mm}$, TL: $35.25 \pm 4.55 \mathrm{~mm}$ (total length: $69.00 \pm 7.90 \mathrm{~mm}$ ). Except for enlarged abdomens, females did not display any clear external morphological signs before breeding (i.e. presence of enlarged endolymphatic glands or calcium carbonate deposits in region of head and neck).

\section{d. Other faunal groups found at the breeding sites}

Several species of invertebrates were observed on or very close to the egg clusters inside the caves. The recorded mollusks included Ratnadvipia irradians (13 occasions), Beddomea albizonata (four occasions), a Cyclophorus sp. and Laevicaulis altae on one occasion each. The arthropods observed included black ants, Technomyrmex albipes (in three sites), two adult cockroaches, several millipedes and an orthopteran. Several spiders and pseudoscorpions were observed in close proximity to the egg clusters. Of these organisms, ants, cockroaches and the orthopteran were observed to be feeding on the shell membrane of newly hatched eggs. No other gecko species were encountered inside studied caves. Cnemaspis scalpensis, Geckoella triedra, Cyrtodactylus fraenatus and Hemidactylus depressus were found in adjoining large trees, among leaflitter and among other boulders in the vicinity. During the night survey on 24 Dec 2005, a large Wolf snake (Lycodon aulicus) was found inside Cave 5.

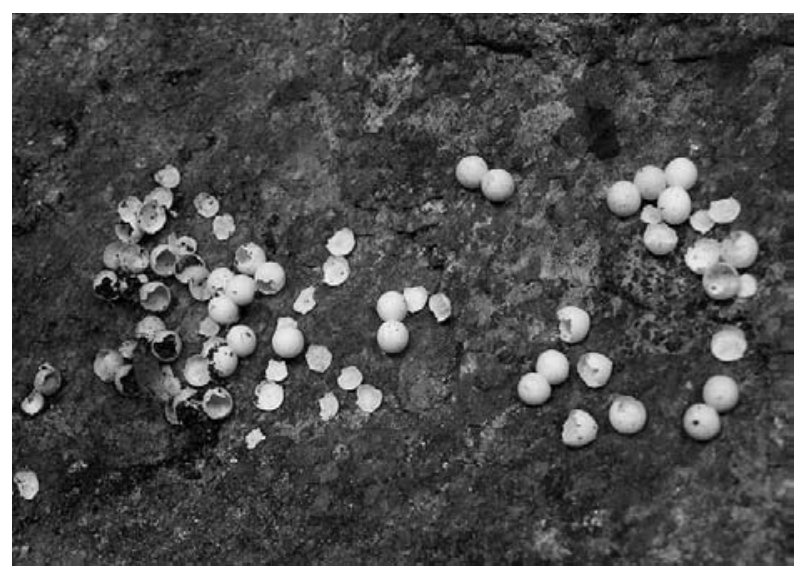

Figure 5: Cluster 1 of Cave 3 on 19 Aug 2005-a probable communalnesting cluster

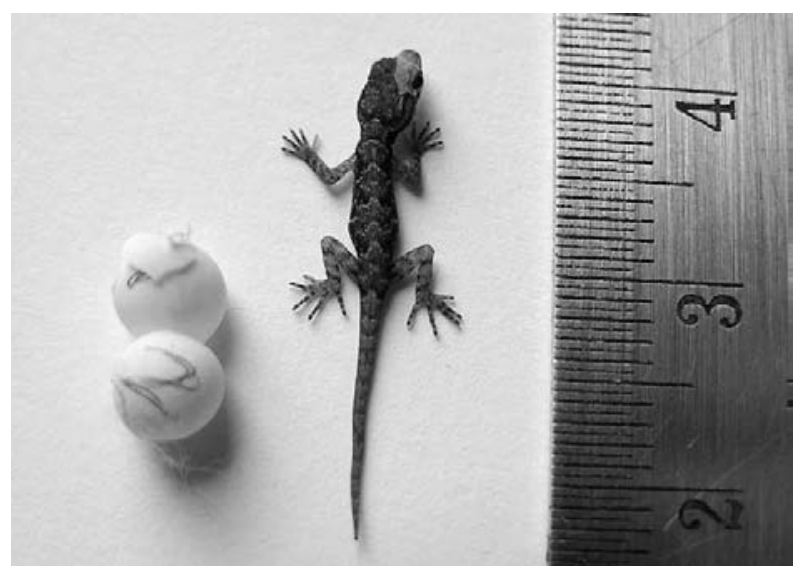

Figure 6: A hatchling incubated in captivity 


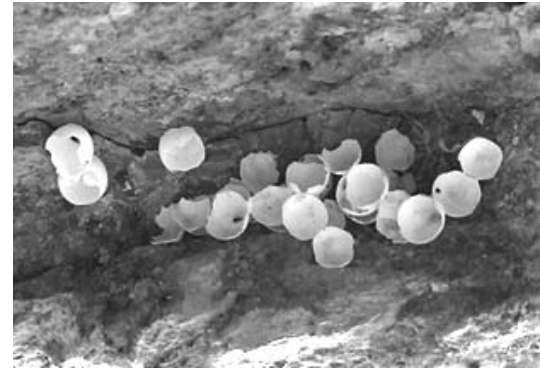

02 July 2005

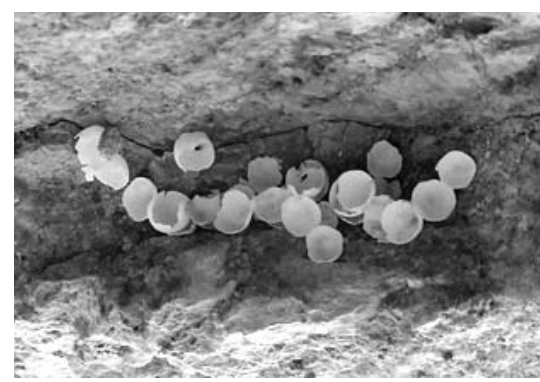

17 September 2005

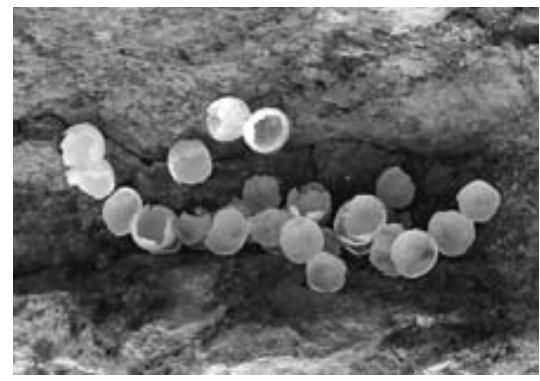

20 November 2005

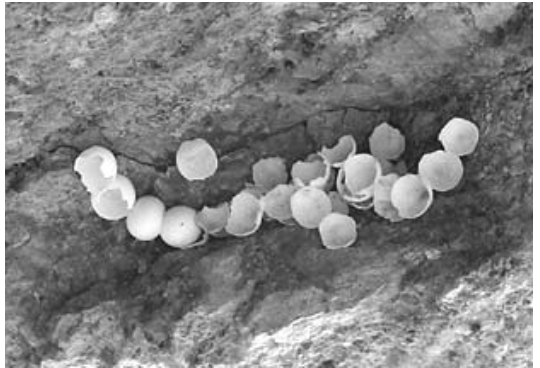

30 July 2005

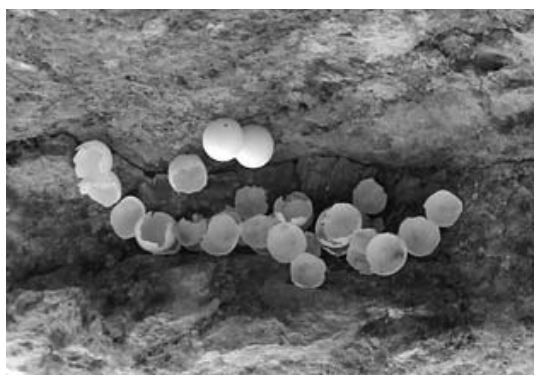

09 October 2005

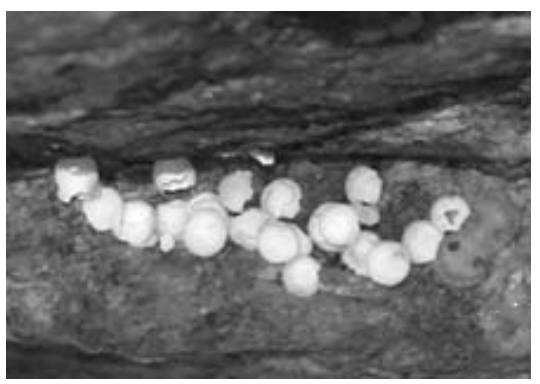

29 January 2006 (note that some eggs are covered by termite mounds)

Figure 7: Egg addition pattern of Cluster 2 of Cave 1 - a probable non-communal nesting cluster (note the addition of eggs in pairs.)

\section{DISCUSSION}

\section{Habitat selection}

At the GFR, C. kandiana showed a clear preference for nesting within caves and in habitats such as beneath the stones, logs etc. in close proximity to caves or boulders. In the Udawattakele Sanctuary, where rocky habitats are few, C. kandiana was observed to live predominantly on large trees, in either tree holes or under the bark, whereas in lower Hantana Forest, geckos were found to be more common in rocky habitats (personal observation). Therefore, it appears that although the species is able to live in several microhabitats, they select rocky habitats over others, whenever available. This behaviour has also been independently recorded in other work ${ }^{12,21}$.
Nesting in caves, especially on high walls and the roof, probably offers the following advantages. Nesting high above the ground probably protects the eggs from terrestrial predators by being less accessible. The dark interior of caves makes the eggs as well as the adults less visible to predators and offers protection from environmental hazards. Caves also provide protection from heavy rains. In addition to caves, communal nests of other geckos have been recorded from termite hills ${ }^{25}$, decayed bark, piles of coconut husks, in the soil, cavities of trees, rock piles ${ }^{26}$, under and within $\operatorname{logs}^{26,27}$, near small streams ${ }^{28}$, under bridges and in crevices on walls (personal observation).

Reproduction in lizards is affected by environmental factors such as ambient temperature ${ }^{29}$, precipitation ${ }^{30}$, and photoperiod ${ }^{31}$. The results showed that there is a wide 
variation in both ambient temperature and light intensity in their habitats, ranging from $23-30{ }^{\circ} \mathrm{C}$ and $00-350$ lux, respectively. Relative humidity $(\mathrm{RH})$ was not measured due to lack of suitable equipment.

\section{Activity periods}

Reptiles exhibit discrete daily and seasonal activity periods. Due to the poikilothermic nature of reptiles, environmental temperature is an important determinant of the activity periods. Within the constraints imposed by the physical environment, biological factors such as food availability, predator avoidance and competition influence their periods of activity. Endogenous factors such as reproductive cycles also play a critical role in governing the periods of activity of reptiles.

\section{Breeding season}

Deraniyagala $^{13}$ reports securing eggs in August, September and November. According to the results of the present study, C. kandiana probably does not show a particular breeding season as eggs were observed throughout the study period, which lasted approximately eight months, suggesting that they most likely breed throughout the year. Since there are no records of sperm retention in this species (or genus) the reduction in the number of eggs during and soon after rainy months may be due to the disruption of mating behaviour during rainy months. The eggs of this species are found more frequently during the drier months, when the humidity is low, which reduces the decomposition action of fungi that may destroy the eggs. The activity of predators is also perhaps less intense during dry seasons.

\section{Egg clusters}

The emergence of hatchlings in pairs suggests that female $C$. kandiana lays two eggs at a time. C. kandiana could be considered as a species with relatively invariant clutch size (i.e. two) because $85 \%$ of the eggs were laid in pairs. The exceptions were separate singles (13\%) and a (probable) single triplet ( $2 \%$ ). But even in the triplet, it seems that two eggs were laid first and the third attached subsequently, either by the same female or a different one. The $~ 50$ gravid Cnemaspis females observed elsewhere had only two eggs each (personal observation). Because females with invariant clutch sizes are unable to increase offspring number, even when sufficient space and energy are available, they may compensate by laying larger eggs or increasing reproductive frequency ${ }^{38}$.

The periodicity of hatching of eggs within clusters suggests that on average females in this population lay clutches of eggs every 1-2 months. They tend to return to the same site for successive ovipositions. Some pairs of eggs hatch out of synchrony and has probably resulted from true communal nesting, where several females have used a common site. The highest number of unhatched eggs observed at a given cluster was 18 . This shows that the cluster size varied between 1-18 eggs in the study area. Large clusters with over 100 either hatched or unhatched eggs have been recorded from the Knuckles Range $^{21}$.

\section{Incubation time}

The incubation time was observed to vary between a probable minimum of 39 days and a probable maximum of 58 days under an average ambient temperature of 24 $\pm 2{ }^{\circ} \mathrm{C}$. Biswas ${ }^{17}$ reported the incubation time to be $49-53$ days for $C$. mysoriensis, a similar species of gecko from India.

\section{Sex ratio}

The sex ratio of the hatchlings is not known as it was difficult to determine sex in hatchlings without dissecting them, as neither hemipenial bulges nor pores were clearly visible externally.

\section{Sex determination}

BothGeneticSexDetermination(GSD)andEnvironmental Sex Determination (ESD) can take place in Gekkonidae ${ }^{39}$. The temperature-sensitive period of irreversible sex determination of geckos lies between embryonic stages 32-37 ${ }^{40}$, which is similar to that in turtles and alligators. Since species of Cnemaspis do not bury their eggs, it is very unlikely that ESD occurs, as it may be difficult for them to maintain conditions associated with ESD (i.e. different incubation temperatures due to deposition in different strata). Studies are necessary to confirm the method of sex determination in these geckos.

\section{Interaction with other fauna}

The observations suggest that an array of insects, including ants, orthopterans, and cockroaches, feed on the shell membranes of the newly hatched eggs. On the other hand, these invertebrates are probably the major food source for adult geckos and the hatchlings. No animals were observed preying or feeding on either hatchlings or adults of $C$. kandiana. However, the Wolf snake (Lycodon aulicus) found inside a cave may have been foraging for geckos. Wolf snakes are nocturnal, terrestrial species with arboreal tendencies and their diet comprises mainly geckos. Two species of wolf snakes, i.e., L. aulicus and L. striatus were recorded from the GFR 
during the study period and $L$. aulicus was observed to enter caves, probably in search of food. Additionally, Cat snakes (Boiga spp.) and Green whip snakes (Ahaetulla nasuta), all of which are arboreal, are also common at the GFR. These snakes are also known to feed on geckos (personal observation). These observations suggest that predator avoidance can also be a reason for these geckos to nest high up in caves, rather than at ground level in the forest or in trees, where predators have better access.

Although the snail $R$. irradians was suspected to feed on the egg shells of geckos to support their calcium requirement, they did not feed on shells under laboratory conditions, even when no other food was supplied. But Pomacea spp. scraping the shells of other individuals of the same species have been observed (personal communication, K.B. Ranawana). However, to build up the shell, snails do have a need for large quantities of calcium in their diet. Some keepers of 'pet' snails are known to feed them with cuttlefish bone and/or eggshells (personal communication, John Rudge). Later it was investigated whether the geckos feed on the broken shells of dead snails for their calcium requirement. But no firm evidence could be obtained in this regard, either. Thus, depending on the observations, it appears that $C$. kandiana and $R$. irradians have no strong, close interaction at the sites, though they share the same habitat.

\section{True communal nesting}

Communal oviposition is the non-incidental deposition of eggs at a shared nest cavity by two or more conspecifics or by members of different genera ${ }^{41,42}$. This oviposition strategy is different from colonial nesting, which is more commonly associated with avian taxa as a cosmopolitan nesting strategy, in which eggs are deposited adjacent to one another at the same general site, but not in the same nest cavity ${ }^{26,41}$. The latter strategy is also shown by certain invertebrate taxa and marine turtles. The first stages of development of parental care in reptiles are represented by merely the choice of optimal egg laying site by females. Conglomeration of individuals and accompanied communal clusters seem to have a number of advantages which are considered usually as functions of a colonial mode of life. It should be associated with several factors such as anti-predatory strategy and synchronization of reproduction ${ }^{43}$. Choice of site for egg incubation may be directly related to habitat and shelter selection that is significant for the survival of the species, especially in small reptiles like geckos, which have no active anti-predatory mechanisms and are limited to using passive defense systems. However, under certain circumstances, communal nesting may select negatively as hatchlings emerging from the same site will compete for common resources.
The potential factors that may influence the communal nesting behaviour in reptiles include (1) constraints (relative scarcity of suitable sites leading species to a multiple use of those available, competition for nesting sites, need of particular microhabitat characteristics) or (2) adaptations (protection from predators, reproductive synchrony, inbreeding avoidance through temperature dependent sex determination, direct fitness benefits $)^{26,28,43-45}$. High sociality can also be a reason for very strong communal egg-laying behaviour, such as in Calodactylodes illingworthorum (personal communication, Sayanthan Biswas).

Among lizards, communal nesting has been registered for a number of lizard species of the genus Anolis $^{26}$, some teiids like Kentropyx calcarata $^{28}$, some gymnophtalmids like Neusticurus ecpleopus ${ }^{28}$ and for several species of geckos. Some gekkonids even display multi-species communal nesting ${ }^{46}$. Communal nests of some teiids, i.e. K. calcarata, may contain more than 800 eggs and the gecko Gonatodes humeralis can oviposit more than 50 eggs in single communal nesting cycle $^{44}$. In Sri Lanka, other than for Cnemaspis species, C.illingworthorum is well-known to conduct communal nesting ${ }^{13,19,47,48}$. Additionally, Deraniyagala ${ }^{13}$ recorded communal nesting areas of the Hemidactylus maculatus hunae from Panamure. Hemidactylus platyurus and the pathenogenetic Lepidodactylus lugubris sometimes lay eggs communally ${ }^{19}$. Apparent communal oviposition was also observed in Hemidactylus frenatus (unpublished data, Somaweera \& Somaweera).

\section{Actual egg-laying strategy}

Based on the cluster sizes, assumed egg-laying frequency in females, incubation time and length of breeding season in the studied populations, the communal egg-laying in this species can be considered as a combined effect of site fidelity of an individual female and the actual communal nesting behaviour of the conspecifics. Depending on the rate of addition of eggs to the clusters and the total number of unhatched eggs present at a given time, it can be assumed that only Cluster 3 of Cave 1; Cluster 2 of Cave 2; Cluster 1 of Cave 3 (Figure 5); Cluster 2 of Cave 3; Cluster 1 of Cave 4 and Cluster 2 of Cave 5 were used as true communal nesting sites during the study period. The other sites were probably used by a single female for her multiple clutches, as the number of eggs present at a given time did not exceed four, and eggs were added as pairs with a gap of approximately one month (as in Cluster 2 in Cave 1 - Figure 7).

The present data suggest that communal nesting in C. kandiana may be due to relative scarcity of 
suitable habitats (C. kandiana predominantly prefers rocky habitats, which are comparatively rare within its range) and microhabitats (locations with no direct incident sunlight) and the resulting competition within a population.

\section{CONCLUSION}

The results of the present study indicate that large aggregations of eggs of $C$. kandiana observed are due both to the same female returning to the same site for oviposition and communal nesting, i.e., several females sharing an egg-laying site. Communal nesting may have occurred due to scarcity of preferred habitats and microhabitats within, and the resulting competition within a population. Inside the studied caves investigated at the GFR, C. kandiana nests at an ambient temperature between $23-30^{\circ} \mathrm{C}$ and a light intensity between 0-350 lux. The eggs are laid predominantly as pairs. The cluster size ranges from 1-18 eggs. Eggs tend to hatch simultaneously in pairs, after an incubation period of a minimum of 39 to a maximum of 58 days. The hatchlings have a total length of 23.5-25.8 $\mathrm{mm}$ at birth. The species does not show clear strong interaction with regard to breeding with the other studied faunal groups at the breeding sites.

\section{Acknowledgement}

Support given by the following persons in various aspects is acknowledged. Dr Sean Doody (University of Canberra) for initially getting me interested in this study, Prof. Mangala de Silva (University of Peradeniya-UOP) for supervising this project, John Rudge (Global Gecko Association), Dr K.B. Ranawana (UOP), Prof. Indraneil Das (Universiti Malaysia Sarawak), Dr Gernot Vogel (University of Heidelberg) for providing information, personal comments and literature, Nilusha Somaweera (UOP), Mendis Wickramasinghe (IUCN, Sri Lanka), Nuwan Bandara (UOP) and Nayana Wijethilake (UOP) for assistance in the field, Prof. Yehudah Werner (Hebrew University of Jerusalem) and Sayanthan Biswas (George Washington University) for their comments towards the improvement of the study.

\section{References}

1. Das I. (1993). Cnemaspis gordongekkoi, a new gecko from Lombok, Indonesia, and the biogeography of Oriental species of Cnemaspis (Squamata: Sauria: Gekkonidae). Hamadryad 18: 1-9.

2. Das I. \& Bauer A.M. (2000). Two new species of Cnemaspis from Tamil Nadu, Southern India. Russian Journal of Herpetology 7(1): 17-28.

3. Das I. \& Sengupta S. (2000). A new species of Cnemaspis (Sauria: Gekkonidae) from Assam, North-Eastern India.
Journal of South Asian Natural History 5(1): 17-24.

4. Kluge A.G. (2001). Gekkotan lizard taxonomy. Hamadryad 26(1): 1-209.

5. Bauer A.M. (2002). Two new species of Cnemaspis (Reptilia: Squamata: Gekkonidae) from Gund, Uttara Kannada, India. Mitteilungen aus dem Hamburgischen Zoologischen Museum und Institute 99: 155-167.

6. Das I. \& Grismer L.L. (2003). Two new species of Cnemaspis Strauch, 1887 (Squamata: Gekkonidae) from the Seribuat Archipelago, Pahang and Johor States, West Malaysia. Herpetologica 59(4): 544-552.

7. Das I. \& Leong T.M. (2004). A new species of Cnemaspis (Sauria: Gekkonidae) from Southern Thailand. Current Herpetology 23(2): 63-72.

8. Das I. (2005). Revision of the genus Cnemaspis Strauch, 1887 (Sauria: Gekkonidae), from the Mentawai \& adjacent archipelagos off Western Sumatra, Indonesia, with the description of four new species. Journal of Herpetology 39(2): 233-247.

9. Mukherjee D., Bhupathy S. \& Nixon A.M.A. (2005). A new species of day gecko (Squamata, Gekkonidae, Cnemaspis) from the Anaikatti Hills, Western Ghats, Tamil Nadu, India. Current Science 89(8): 1326-1328.

10. Bauer A.M., de Silva A., Greenbaum E. \& Jackman T. (2007). A new species of day gecko from high elevation in Sri Lanka, with a preliminary phylogeny of Sri Lankan Cnemaspis (Reptilia, Squamata, Gekkonidae). Mitteilungen aus dem Zoologischen Museum in Berlin, Supplement 83: 22-32.

11. Wickramasinghe L.J.M. \& Munindradasa D.A.I. (2007). Review of the genus Cnemaspis Strauch, 1887 (Sauria: Gekkonidae) in Sri Lanka with the description of five new species. Zootaxa 1490: 1-63.

12. Manamendra-Arachchi K., Batuwita S. \& Pethiyagoda R. (2007). A taxonomic revision of the Sri Lankan day-geckos (Reptilia: Gekkonidae: Cnemaspis), with description of new species from Sri Lanka and Southern India. Zeylanica 7(1): 9-122.

13. Deraniyagala P.E.P. (1953). A Colored Atlas of Some Vertebrates from Ceylon Vol. 2:Tetrapod Reptilia. Ceylon National Museums, Colombo.

14. Bhupathy S. \& Nikon A.M.A. (2002). Communal egg laying by Cnemaspis indica in Mukurthi National Park, Western Ghats. Journal of Bombay Natural History Society 99: 330-332.

15. Biswas S. \& Ishwar N.M. (2006). Cnemaspis (Oriental dwarf geckos) communal oviposition. Herpetological Review 37: 83-84.

16. Werner Y.L. \& Chou L.M. (2002). Observations on the ecology of the arrhythmic equatorial gecko Cnemaspis kendallii in Singapore (Sauria: Gekkoninae). The Raffles Bulletin of Zoology 50(1): 185-196.

17. Biswas S. (2005). Cnemaspis mysoriensis (Mysore dwarf gecko): reproduction. Herpetological Bulletin 93: 21-22.

18. Deraniyagala P.E.P. (1932). The Gekkonidae of Ceylon. Spolia Zeylanica 16(3): 291-311.

19. Das I. \& de Silva A. (2005). A Photographic Guide to Snakes and Other Reptiles of Sri Lanka. pp. 144. New Holland Publishers Ltd, UK. 
20. Ratnayake N.D. (2004). The Sri Lankan day-geckos of the genus Cnemaspis. Gekko 4 (1): 39-44.

21. de Silva A., Bauer A.M., Goonawardene S., Drake J., Nathaniel S. \& de Silva P. (2005). Some observations on the geckos inhabiting the Knuckles Massif. The diversity of the Dumbara mountains (The Knuckles massif, Sri Lanka). With special reference to its herpetofauna. Lyriocephalus Special issue 6 (1\&2): 125-133.

22. Henkel F.W. \& Schmidt W. (2003). Geckos-Professional Breeders Series. Edition Chimaira, Franfurt am Main, Germany.

23. Basnayake B.M.K.M.K. (1998). Biodiversity of Gannoruwa Forest and its sustainable management. MSc thesis Postgraduate Institute of Science, University of Peradeniya, Peradeniya.

24. Ashton M.S., Gunathileke S., de Zoysa N., Dassanayake M.D., Gunathileke N. \& Wijesundara S. (1997). A Field Guide to Common Trees and Shrubs of Sri Lanka. pp. 431, Wildlife Heritage Trust of Sri Lanka.

25. Greer A.E. (1967). The ecology and behavior of two sympatric Lygodactylus geckos. Breviora 268: 1-19.

26. Rand A.S. (1967). Communal egg laying in anoline lizards. Herpetologica 23: 227-231.

27. Estrada A.R. (1987). Anolis argillaceus (Sauria: Iguanidae): un nuevo caso de puestas comunales en anolis cubanos. Poeyana 353: 1-9.

28. Magnusson W. \& Lima A. (1984). Perennial communal nesting by Kentropyx calcaratus. Journal of Herpetology 18(1):73-75.

29. Marion K.R. (1982). Reproductive cues for gonadal development in temperate reptiles: temperature and photoperiod effects on the testicular cycle of the lizard Sceloporus undulatus. Herpetologica 38:26-39.

30. Guillette L.J. Jr. \& Casas-Andreu G. (1987). The reproductive biology of the high elevation Mexican lizard, Barisia imbricata. Herpetologica 43: 29-38.

31. Licht P. (1967). Environmental control of annual testicular cycles in the lizard Anolis carolinensis I. Interaction of light and temperature in the initiation of testicular recrudescence. Journal of Experimental Zoology 165: 505-516.

32. 3M Scotchlite (1998). Reflective material. Technical Data Sheet. 3M, UK, Ireland.

33. Fitch H.S. (1970). Reproductive Cycles of Lizards and Snakes. University of Kansas Museum of Natural History Miscellaneous Publication 52: 1-247.

34. Kluge A.G. (1967). Higher taxonomic categories of gekkonid lizards and their evolution. Bulletin at the American Museum of Natural History 135: 1-59.

35. Bauer A.M. (1989). Extracranial endolymphatic sacs in
Eurydactylodes (Reptilia: Gekkonidae), with comments on endolymphatic function in lizards. Journal of Herpetology 23(2): 172-175.

36. Ruth E.S. (1918). A study of the calcium glands in the common Philippine house lizards. Phillipine Journal of Science (B) Tropical Medicine 13: 311-319.

37. Bustard H.R. (1968). The egg-shell of gekkonid lizards: a taxonomic adjunct. Copeia 1968: 162-164.

38. Doughty P. (1997). The effects of 'fixed' clutch sizes on lizard life-histories: reproduction in the Australian velvet gecko, Oedura lesueurii. Journal of Herpetology 31(2): 266-272.

39. Viets B.E., Ewert M.A., Talent L.G. \& Nelson C.E. (1994). Sex-determining mechanisms in squamate reptiles. Journal of Experimental Zoology 270(1): 45-56.

40. Bull J.J. (1987). Temperature-sensitive periods of sex determination in a lizard - similarities with turtles and crocodilians. Journal of Experimental Zoology 241(1): 143-148.

41. Espinoza R.E. \& Lobo F. (1996). Possible communal nesting in two species of Liolaemus lizards (Iguania: Tropiduridae) from northern Argentina. Herpetological Natural History 4: 65-68.

42. Krysko K.L., Kenneth L., Sheehy C.M. \& Hooper A.N. (2003). Interspecific communal oviposition and reproduction of four species of lizards (Sauria: Gekkonidae) in the lower Florida Keys. Amphibia-Reptilia 24: 390396.

43. Ananjeva N.B. \& Orlov N.L. (1995). Communal clutches in Alsophylax pipiens in southern Mongolia. Russian Journal of Herpetology 2(2): 142-147.

44. Oda W.Y. (2004). Communal egg laying by Gonatodes humeralis (Sauria, Gekkonidae) in Manaus primary and secondary forest areas. ACTA Amazonica 34(2): 331-332.

45. Shine R. (1999). Why is sex determined by nest temperature in many reptiles? Trends in Ecology and Evolution 14(5): 186-189.

46. Vitt L.J., Zani A.A. \& Barros M. (1997). Ecological variation among populations of the gekkonid lizard Gonatodes humeralis in the Amazon Basin. Copeia 1997: 32-43.

47. Wickramasinghe M. \& Somaweera R. (2003). Distribution and current status of the endemic geckos of Sri Lanka. Gekko 3(1): 2-13.

48. de Silva A., Bauer A.M., Austin C.C., Goonawardene S., Hawke Z., Vanneck V., Drion A., de Silva P., Perera B.J.K, Jayaratne R.L. \& Goonasekera M.M. (2004). Distribution and natural history of Calodactylodes illingworthorum (Reptilia: Gekkonidae) in Sri Lanka: preliminary findings. Lyriocephalus 5:192-198. 